\title{
Optimizing the Resultativeness of Adapting Economic Entity to the Conditions of Digitalization
}

\author{
By Angela Mottaeva ${ }^{1}$, Julia Stepanova ${ }^{2}$, Natalia Meshkova ${ }^{2}$, Galina Semenova ${ }^{3}$
}

\begin{abstract}
The paper discusses theoretical approaches to the concept of resultativeness, considers and substantiates modern approaches to adapting an economic entity to the conditions of digitalization. In this study, a formula for calculating the resultativeness of adaptation was established, taking into account the potential capabilities of an economic entity. On the basis of the proposed formula, possible quantitative values of the resultativeness of adapting an economic entity to the conditions of digitalization are studied and their interpretation is provided. The paper reveals the economic essence of the absolute and relative differences between the performance indicators of an economic entity, which describe the result of adaptation to digitalization conditions. The components of adaptation resultativeness and a list of expressions describing them are presented. In the course of the study, the resultativeness of adaptation was determined using two research methods: deductive and inductive ones. Based on the results of the study, an algorithm for finding the optimal value of the resultativeness of adaptation in the context of digitalization and its costs is proposed. This algorithm will allow determining the optimal value of the resultativeness of adaptation in the context of digitalization and its costs, based on the calculation of the quantitative value of the resultativeness of adaptation of the enterprise and a retrospective analysis of the components of the resultativeness and costs of adaptation using the Nelder-Mead simplex method.
\end{abstract}

Keywords: resultativeness, adaptation, optimization, digitalization of the economy.

\section{Introduction}

In recent years, the conditions for conducting economic activities have undergone significant changes. This is primarily caused by the deep implementation of information and communication technologies in business processes at all levels, from the economy of a single enterprise to the global economy. The increasing role of information and knowledge in business, the need to reduce production costs and the rapid development of digital information technologies have given rise to an almost new type of economy - the digital economy (Kuntzman, 2017). Information and communication technologies have become more than just digital support for business processes. Absolutely all economic entities have to conduct economic activity in the conditions of digitalization. This makes it necessary to consider the issues of adaptation of economic entities to the conditions of digitalization. Today, society is entering the era of the digital economy, which is significantly changing the usual areas (Valenduk, \& Vendramin, 2016). The digital economy is a type of economy characterized by the active introduction and actual application of digital technologies for collecting, storing, processing, transforming and

\footnotetext{
| ${ }^{1}$ National Research University Moscow State University of Civil Engineering, Russian Federation. 
transmitting data in absolutely all spheres of human activity (Wetherbe, McLean, Leidner, \& Turban, 2006). Digitalization is the basis of the digital economy, a global development trend that determines the development of the economy and society, and forms the digital economy. Digitalization is the main modern trend in the development of the economy and society, based on the transition to a digital format for presenting information, which is aimed at increasing the resultativeness of the economy and improving the quality of life. It contributes to the consistent improvement of all business processes of the economy and related social spheres. This iimprovement is based on an increase in the speed of interchange, accessibility and security of information, as well as on the increasing role of automation as a basis for digitalization (Khalin, \& Chernov, 2018). At the same time, the further existence and development of any economic entity is possible only on condition that the adaptation is effective. In order to solve the problem of achieving the resultativeness of adapting an economic entity to the conditions of digitalization, it is necessary to understand the economic meaning of the resultativeness of adaptation and its components (Afanasyev, Staroverova, \& Urintsov, 2016).

\section{Methodology}

To determine the resultativeness of adaptation, the point of view of most scientists on the resultativeness as the degree of achievement of the planned results (planned tasks, goals) is of particular interest. P. Drucker considered resultativeness as a consequence of "doing the right thing" (Drucker, 2007). V.A. Kachalov presents resultativeness as a measure in which the company has implemented the planned activities and achieved the planned results in the implementation of the quality policy and the achievement of quality objectives (Kachalov, 2007). R.Z. Darmits views performance as a complex, multi-element, multi-criteria phenomenon that is characterized by a number of indicators of the degree of achievement of the established goals of a business entity and is an "external manifestation" (negative, positive) of its activities (Darmits, \& Vatsik, 2010). Scientists E. Moseng and P. Bredap defined resultativeness based on the concepts: effectiveness, economy, flexibility. Their definition is fairly new, which serves as a basis for improving the concept of resultativeness. The modern American researcher of the problem of the effectiveness and resultativeness of a company, G. Cokins, confirms that resultativeness and effectiveness are equally important: "First, choose a strategy, define goals, and then achieve them with the least possible resources" (Cokins, 2015). Scientists S. Robbins and M. Coulter define the concept of "resultativeness" as follows: "resultativeness is an indicator that reflects how the organization has managed to achieve its goals" (Robbins, Stephen, Coulter, 2007).

In this case, the resultativeness is calculated by the ratio of the actual achieved results to the planned ones. In the work, we accept the statement that the resultativeness of adaptation will be equal to $100 \%$ if the result of adaptation is also $100 \%$, i.e. the planned result of adaptation will be achieved - a minimum of inconsistency with the external environment, which is described by the desired values of indicators of the impact of environmental factors, including digitalization conditions. But an economic entity does not always have enough resources to achieve the desired values of indicators. In this 
regard, potentially possible or planned values of indicators are established. After carrying out the adaptation actions, the actual values are obtained.

It is possible to find out the reasons for obtaining a specific value of the resultativeness of adaptation to the conditions of the digital economy if we trace the relationship between the actual (AV), potentially possible (PV) and desirable (DV) values of indicators that describe the state of an economic entity during adaptation at the beginning and end of the study period. An economic entity has the ability to establish a set of indicators independently, depending on the area, volume of its activities and the density of connection with digital technologies.

In previous studies, the authors established a formula for calculating the resultativeness of adaptation $(\mathrm{R})$ :

$$
\mathrm{R}=\frac{\left|\mathrm{DV}_{\mathrm{F}}-\mathrm{AV}_{\mathrm{F}}\right|-\left|\mathrm{DV}_{0}-\mathrm{AV}_{0}\right|}{-\left|\mathrm{DV}_{0}-\mathrm{AV}_{0}\right|}
$$

It should be noted that formula (1) reflects the ideal case when an economic entity has made a decision to achieve the desired values of indicators (DV) and has the necessary resources for this. However, there are situations when an economic entity will not make efforts to fully achieve the requirements of the external environment, i.e. the desired values of indicators (DV), specifically (Kuntzman, 2016):

- an economic entity does not have enough resources to meet the requirements of the external environment (funds, raw materials, materials, technologies, specialists, time);

- an economic entity has resources, but does not want to achieve full compliance with the external environment, for example, due to the fact that a change in the influence of an environmental factor only indirectly affects the main results of an economic entity performance.

In such cases, the economic entity establishes the planned or potentially possible values of indicators (PV) reflecting the results of the economic entity's activities, subject to adaptation. In this case, we can say that the planned result of adaptation is the planned reduction of the discrepancy between economic entities and the external environment.

Taking into account the potential capabilities of an economic entity, the formula for calculating the resultativeness of adaptation takes the form:

$$
R=\frac{\left|\mathrm{DV}_{\mathrm{F}}-\mathrm{AV}_{\mathrm{F}}\right|-\left|\mathrm{DV}_{0}-\mathrm{AV}_{0}\right|}{\left|\mathrm{DV}_{\mathrm{F}}-\mathrm{PV}_{\mathrm{F}}\right|-\left|\mathrm{DV}_{0}-\mathrm{AV}_{0}\right|}
$$

This formula, in contrast to formula (1), takes into account the potential capabilities of an economic entity and its intentions to achieve compliance with the digitalization conditions. In this case, as we see from figure 1, in addition to the actual result of adaptation, the resultativeness depends on the established planned result of adaptation (planned reduction of nonconformity). It is because of this that the same value 
of the actual result of adaptation can give different values of the resultativeness of adaptation.

The resultativeness calculated by the formula (2) can take the following values (Table 1).

Table 1: Interpretation of the obtained quantitative values of the resultativeness of adaptation of an economic entity to the conditions of digitalization

\begin{tabular}{|c|c|}
\hline $\begin{array}{l}\text { Quantitative value } \\
\text { of the } \\
\text { resultativeness of } \\
\text { adaptation }\end{array}$ & $\begin{array}{l}\text { Interpretation of the obtained quantitative value of the } \\
\text { resultativeness of adaptation }\end{array}$ \\
\hline$P=1(100 \%)$ & $\begin{array}{l}\text { the obtained value indicates } 100 \% \text { resultativeness of adaptation of } \\
\text { the economic entity to the digitalization conditions, i.e. the actual result of } \\
\text { adaptation is equal to the planned result of adaptation }\end{array}$ \\
\hline$P=0$ & $\begin{array}{l}\text { it is possible if the actual result of adaptation (the numerator of } \\
\text { formula (2)) equals } 0 \text {. This indicates that the adaptation is ineffective, i.e. the } \\
\text { level of inconsistency between the economic entity and the external } \\
\text { environment remains unchanged }\left(\mathrm{H}_{0}=\mathrm{H}_{\mathrm{f}}\right)\end{array}$ \\
\hline - & $\begin{array}{l}\text { it is impossible to calculate the resultativeness of adaptation in the } \\
\text { event that the planned result of adaptation is equal to } 0 \text {, i.e. if the economic } \\
\text { entity considers it appropriate to maintain the existing level of mismatch } \\
\text { between the actual and the desired state of activity (mathematically, this will } \\
\text { be a reflection of the impossibility of dividing by } 0 \text {, i.e. the denominator of } \\
\text { formula } 2 \text { will be } 0 \text { ) }\end{array}$ \\
\hline $\mathrm{P}>0$ & $\begin{array}{l}\text { the adaptation was effective; how effective it was is evidenced by the } \\
\text { obtained value of resultativeness }\end{array}$ \\
\hline $\mathrm{P}<0$ & $\begin{array}{l}\text { indicates that the adaptation carried out is ineffective, the obtained } \\
\text { value speaks of the percentage of decrease in resultativeness compared to the } \\
\text { initial value }\end{array}$ \\
\hline
\end{tabular}

The relationship between $\mathrm{DV}_{0}, \mathrm{PV}_{0}, \mathrm{AV}_{0}$ and $\mathrm{DV}_{\mathrm{f}}, \mathrm{PV}_{\mathrm{f}}, \mathrm{AV}_{\mathrm{f}}$, which express the results of the activity of an economic entity before and after the process of adaptation to digitalization conditions, can be graphically represented in the form of Figure 1. 


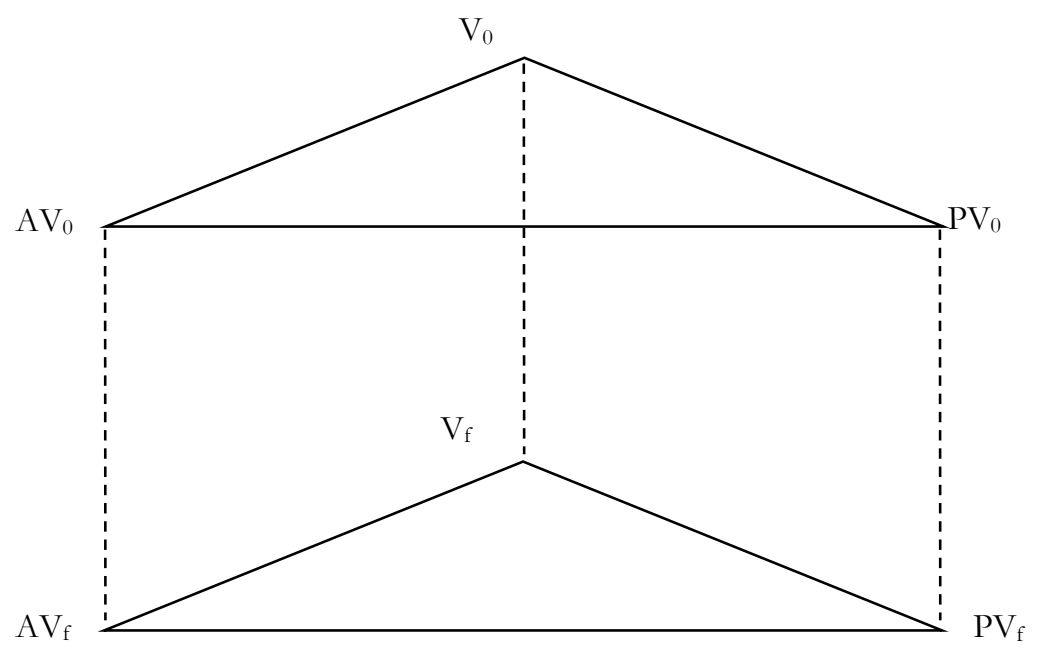

Figure 1. Change in the results of the activity of an economic entity over time under the influence of adaptation actions

The presented plotting is caused by the following factors:

- between $\mathrm{DV}_{0}, \mathrm{PV}_{0}, \mathrm{AV}_{0}$ and $\mathrm{DV}_{\mathrm{f}}, \mathrm{PV}_{\mathrm{f}}, \mathrm{AV}_{\mathrm{f}}$, time passes from the beginning to the end of the adaptation actions;

- first, $A V_{0}$ is calculated and $\mathrm{DV}_{0}$ is established, which reflect the requirements of the external environment, on their basis and depending on the capabilities of the economic entity, $\mathrm{PV}_{0}$ is established.

To reveal the dependence of the resultativeness of adaptation on certain results of the activity of an economic entity, we will consider the relationship between the elements in Table 2.

Table 2: Matrix of absolute differences and relationships between the performance of an economic entity, which are formed under the influence of adaptation actions

\begin{tabular}{|c|c|c|c|c|c|c|}
\hline & $\mathrm{DV}_{0}$ & $\mathrm{PV}_{0}$ & $\mathrm{AV}_{0}$ & $\mathrm{DV}_{\mathrm{f}}$ & $P V_{f}$ & $\mathrm{AV}_{\mathrm{f}}$ \\
\hline $\mathrm{DV}_{0}$ & - & $\begin{array}{l}\mathrm{DV}_{0^{-}} \mathrm{PV}_{0} \\
\mathrm{PV}_{0} / \mathrm{DV}_{0}\end{array}$ & $\begin{array}{l}\mathrm{DV}_{0^{-}} \mathrm{AV}_{0} \\
\mathrm{AV}_{0} / \mathrm{DV}_{0}\end{array}$ & $\begin{array}{l}\mathrm{DV}_{\mathrm{f}}- \\
\mathrm{DV}_{0} ; \\
\mathrm{DV}_{0} / \mathrm{DV}_{\mathrm{f}}\end{array}$ & $\begin{array}{l}\mathrm{DV}_{0^{-}} \mathrm{PV}_{\mathrm{f}} \\
\mathrm{PV}_{\mathrm{f}} / \mathrm{DV}_{0}\end{array}$ & $\begin{array}{l}\mathrm{DV}_{0^{-}} \mathrm{AV}_{\mathrm{f}} \\
\mathrm{AV}_{\mathrm{f}} / \mathrm{DV}_{0}\end{array}$ \\
\hline $\mathrm{PV}_{0}$ & - & - & $\begin{array}{l}\mathrm{PV}_{0^{-}} \mathrm{AV}_{0} \\
\mathrm{AV}_{0} / \mathrm{PV}_{0}\end{array}$ & $\begin{array}{l}\mathrm{DV}_{\mathrm{f}}- \\
\mathrm{PV}_{0} ; \\
\mathrm{PV}_{0} / \mathrm{DV}_{\mathrm{f}}\end{array}$ & $\begin{array}{l}\mathrm{PV}_{\mathrm{f}}-\mathrm{PV}_{0} ; \\
\mathrm{PV}_{\mathrm{f}} / \mathrm{PV}_{0}\end{array}$ & $\begin{array}{l}\mathrm{PV}_{0^{-}} \mathrm{AV}_{\mathrm{f}} \\
\mathrm{AV}_{\mathrm{f}} / \mathrm{PV}_{0}\end{array}$ \\
\hline $\mathrm{AV}_{0}$ & - & - & - & $\begin{array}{l}\mathrm{DV}_{\mathrm{f}}- \\
\mathrm{AV}_{0} ; \\
\mathrm{AV}_{0} / \mathrm{DV}_{\mathrm{f}}\end{array}$ & $\begin{array}{l}\mathrm{PV}_{\mathrm{f}}-\mathrm{AV}_{0} \\
\mathrm{AV}_{0} / \mathrm{PV}_{\mathrm{f}}\end{array}$ & $\begin{array}{l}A V_{\mathrm{f}}-A V_{0} \\
A V_{\mathrm{f}} / A V_{0}\end{array}$ \\
\hline $\mathrm{DV}_{\mathrm{f}}$ & - & - & - & - & $\begin{array}{l}\mathrm{DV}_{\mathrm{f}}-\mathrm{PV}_{\mathrm{f}} ; \\
\mathrm{PV}_{\mathrm{f}} / \mathrm{DV}_{\mathrm{f}}\end{array}$ & $\begin{array}{l}\mathrm{DV} V_{\mathrm{f}}-\mathrm{AV}_{\mathrm{f}} \\
\mathrm{\kappa} ; \\
\mathrm{AV}_{\mathrm{f}} / \mathrm{DV}_{\mathrm{f}}\end{array}$ \\
\hline $\mathrm{PV}_{\mathrm{f}}$ & - & - & - & - & - & $\begin{array}{l}P V_{f}-A V_{f} \\
A V_{f} / P V_{f}\end{array}$ \\
\hline$A V_{f}$ & - & - & - & - & - & - \\
\hline
\end{tabular}


Let's reveal the economic essence of the absolute and relative differences in table 3.

Table 3: The economic essence of the absolute and relative differences between the performance indicators of an economic entity, which describe the result of adaptation to digitalization conditions

\begin{tabular}{|c|c|c|}
\hline $\begin{array}{l}\text { Difference } \\
\text { (expression) }\end{array}$ & Economic essence & Characteristic \\
\hline \multicolumn{3}{|c|}{ Absolute differences } \\
\hline $\mathrm{DV}_{0}-\mathrm{PV}_{0}$ & $\begin{array}{l}\text { Difference between the } \\
\text { predicted requirements of the external } \\
\text { environment and the potential } \\
\text { capabilities of an economic entity at } \\
\text { the beginning of adaptation actions }\end{array}$ & $\begin{array}{l}\text { Can be used to assess the } \\
\text { resource capacity of an economic entity. } \\
\text { Characterizes the discrepancy between } \\
\text { the potential capabilities of an economic } \\
\text { entity and the requirements of the } \\
\text { external environment at the initial } \\
\text { moment of time }\end{array}$ \\
\hline $\mathrm{DV}_{0}-\mathrm{AV}_{0}$ & $\begin{array}{l}\text { The size of the discrepancy } \\
\text { between the predicted requirements of } \\
\text { the external environment and the } \\
\text { actual results of activities at the } \\
\text { beginning of adaptation actions }\end{array}$ & $\begin{array}{l}\text { Used to determine the result } \\
\text { of adaptation }\end{array}$ \\
\hline $\mathrm{DV}_{\mathrm{f}}-\mathrm{DV}_{0}$ & $\begin{array}{l}\text { Difference between the } \\
\text { actual and projected requirements of } \\
\text { the external environment }\end{array}$ & $\begin{array}{l}\text { Can be used to assess the } \\
\text { ability to predict }\end{array}$ \\
\hline $\mathrm{DV}_{0}-\mathrm{PV}_{\mathrm{f}}$ & $\begin{array}{l}\text { Difference between the } \\
\text { predicted requirements of the external } \\
\text { environment and the potential } \\
\text { capabilities of an economic entity at } \\
\text { the time of changing the influence of } \\
\text { the external factor }\end{array}$ & $\begin{array}{l}\text { Can be used to assess the } \\
\text { resource capacity of an economic entity. } \\
\text { Can be used to assess the increase in } \\
\text { resource capacity }\end{array}$ \\
\hline $\mathrm{DV}_{0}-\mathrm{AV}_{\mathrm{f}}$ & $\begin{array}{l}\text { Difference between the } \\
\text { predicted requirements of the external } \\
\text { environment and the actual results of } \\
\text { the activity of an economic entity at } \\
\text { the time of changing the influence of } \\
\text { the environmental factor (at the final } \\
\text { moment of time) }\end{array}$ & $\begin{array}{l}\text { Can be used to assess the } \\
\text { ability of an economic entity to reduce } \\
\text { non-compliance with digitalization } \\
\text { conditions. Shows how the actual end } \\
\text { results do not match the forecast. Can } \\
\text { characterize the ability to achieve set } \\
\text { goals }\end{array}$ \\
\hline $\mathrm{PV}_{0}-\mathrm{AV}_{0}$ & $\begin{array}{l}\text { Difference between the } \\
\text { potential capabilities of an economic } \\
\text { entity and the actual results of activities } \\
\text { at the initial moment of time. } \\
\text { Inconsistency of the actual results of } \\
\text { activities with the potential capabilities } \\
\text { of an economic entity at the initial } \\
\text { moment of time }\end{array}$ & $\begin{array}{l}\text { Characterizes the ability of an } \\
\text { economic entity to achieve its goals at } \\
\text { the initial moment of time }\end{array}$ \\
\hline $\mathrm{DV}_{\mathrm{f}}-\mathrm{PV}_{0}$ & $\begin{array}{l}\text { The size of the discrepancy } \\
\text { between the final requirements of the } \\
\text { external environment and the initial } \\
\text { potential capabilities of an economic } \\
\text { entity }\end{array}$ & $\begin{array}{l}\text { Characterizes the actual initial } \\
\text { resource capacity of an economic entity }\end{array}$ \\
\hline$P V_{f}-P V_{0}$ & $\begin{array}{l}\text { Changes in the potential of } \\
\text { an economic entity during the } \\
\text { implementation of adaptation actions }\end{array}$ & $\begin{array}{l}\text { Characterizes the increase or } \\
\text { decrease in the resource capacity of an } \\
\text { economic entity during the } \\
\text { implementation of adaptation actions. }\end{array}$ \\
\hline
\end{tabular}




\begin{tabular}{|c|c|c|}
\hline & & $\begin{array}{l}\text { Can characterize the ability to predict the } \\
\text { potential of an economic entity }\end{array}$ \\
\hline$P V_{0}-A V_{f}$ & $\begin{array}{l}\text { Difference between the } \\
\text { goals set by an economic entity and the } \\
\text { actual achieved results }\end{array}$ & $\begin{array}{l}\text { Characterizes the ability to } \\
\text { complete the task with the necessary } \\
\text { resources }\end{array}$ \\
\hline $\mathrm{DV}_{\mathrm{f}-}-\mathrm{AV}_{0}$ & $\begin{array}{l}\text { The difference between the } \\
\text { actual requirements of the external } \\
\text { environment and the results of the } \\
\text { activity of an economic entity at the } \\
\text { beginning of adaptation actions }\end{array}$ & $\begin{array}{l}\text { Characterizes the initial actual } \\
\text { inconsistency of an economic entity with } \\
\text { the external environment }\end{array}$ \\
\hline$P V_{\mathrm{f}}-A V_{0}$ & $\begin{array}{l}\text { The difference between the } \\
\text { potential capabilities of an economic } \\
\text { entity at the final time and the initial } \\
\text { actual results of activities }\end{array}$ & $\begin{array}{l}\text { Characterizes the discrepancy } \\
\text { between the actual potential capabilities } \\
\text { of an economic entity and the actual } \\
\text { results of activities at the initial moment } \\
\text { of time }\end{array}$ \\
\hline$A V_{\mathrm{f}}-A V_{0}$ & $\begin{array}{l}\text { Changes in the actual results } \\
\text { of the activity of an economic entity } \\
\text { due to adaptation actions }\end{array}$ & $\begin{array}{l}\text { Characterizes the absolute } \\
\text { value of the applied efforts to achieve } \\
\text { the set task }\end{array}$ \\
\hline$D V_{f-P V}$ & $\begin{array}{l}\text { Difference between the } \\
\text { actual requirements of the external } \\
\text { environment and the actual potential } \\
\text { capabilities of an economic entity }\end{array}$ & $\begin{array}{l}\text { Characterizes the discrepancy } \\
\text { between the resource capacity of an } \\
\text { economic entity and the requirements of } \\
\text { the external environment at the final } \\
\text { time }\end{array}$ \\
\hline$D V_{\mathrm{f}}-\mathrm{DV} V_{\mathrm{f}}$ & $\begin{array}{l}\text { The size of the } \\
\text { inconsistency with the external } \\
\text { environment at the final time (after } \\
\text { carrying out adaptation actions) }\end{array}$ & $\begin{array}{l}\text { Characterizes the final } \\
\text { inconsistency with the external } \\
\text { environment. Used to determine the } \\
\text { result of adaptation }\end{array}$ \\
\hline$P V_{\mathrm{f}}-A V_{f}$ & $\begin{array}{l}\text { Difference between the } \\
\text { actual potentialities of an economic } \\
\text { entity and the actual results achieved }\end{array}$ & $\begin{array}{l}\text { Characterizes the ability of an } \\
\text { economic entity to achieve its goals, use } \\
\text { the existing potential }\end{array}$ \\
\hline \multicolumn{3}{|c|}{ Relative differences } \\
\hline $\mathrm{PV}_{0} / \mathrm{DV}_{0}$ & $\begin{array}{l}\text { Resource capacity of an } \\
\text { economic entity at the beginning of } \\
\text { adaptation actions }\end{array}$ & $\begin{array}{l}\text { Characterizes the degree of } \\
\text { provision of an economic entity with } \\
\text { resources to meet the requirements of } \\
\text { the external environment at the initial } \\
\text { moment of time }\end{array}$ \\
\hline $\mathrm{AV}_{0} / \mathrm{DV}_{0}$ & $\begin{array}{l}\text { Compliance with the } \\
\text { external environment at the beginning } \\
\text { of adaptation actions }\end{array}$ & $\begin{array}{l}\text { Characterizes the degree of } \\
\text { compliance of the results of the activity } \\
\text { of an economic entity with the } \\
\text { requirements of the external } \\
\text { environment at the beginning of } \\
\text { adaptation actions; compliance with the } \\
\text { external environment at the start of } \\
\text { adaptation actions }\end{array}$ \\
\hline $\mathrm{AV}_{0} / \mathrm{PV}_{0}$ & $\begin{array}{l}\text { Resultativeness of an } \\
\text { economic entity at the beginning of } \\
\text { adaptation actions }\end{array}$ & $\begin{array}{l}\text { Degree of achievement of } \\
\text { potentially possible results of the activity } \\
\text { of an economic entity at the beginning } \\
\text { of adaptation actions }\end{array}$ \\
\hline $\mathrm{DV}_{0} / \mathrm{DV}_{\mathrm{f}}$ & $\begin{array}{l}\text { Resultativeness of } \\
\text { predicting the strength of the external } \\
\text { environment }\end{array}$ & $\begin{array}{l}\text { Characterizes the ability of an } \\
\text { economic entity to predict the impact of } \\
\text { the external environment and their scale }\end{array}$ \\
\hline
\end{tabular}




\begin{tabular}{|c|c|c|}
\hline $\mathrm{PV}_{0} / \mathrm{DV}_{\mathrm{f}}$ & $\begin{array}{c}\text { Actual initial resource } \\
\text { capacity of an economic entity }\end{array}$ & $\begin{array}{l}\text { Characterizes the degree of } \\
\text { initial resource endowment of an } \\
\text { economic entity to achieve the actual } \\
\text { requirements of the external } \\
\text { environment }\end{array}$ \\
\hline $\mathrm{AV}_{0} / \mathrm{DV}_{\mathrm{f}}$ & $\begin{array}{l}\text { The actual degree of } \\
\text { compliance with the external } \\
\text { environment at the beginning of } \\
\text { adaptation actions. }\end{array}$ & $\begin{array}{l}\text { Characterizes the degree of } \\
\text { compliance of the initial actual results of } \\
\text { the activity of an economic entity with } \\
\text { the actual requirements of the external } \\
\text { environment. Characterizes the chances } \\
\text { of an economic entity with initial } \\
\text { performance results to achieve } \\
\text { compliance with the external } \\
\text { environment }\end{array}$ \\
\hline $\mathrm{PV}_{\mathrm{f}} / \mathrm{DV}_{0}$ & $\begin{array}{l}\text { The ratio of the actual } \\
\text { potential capabilities of an economic } \\
\text { entity to the predicted desired values } \\
\text { of the performance indicators of an } \\
\text { economic entity }\end{array}$ & $\begin{array}{l}\text { Characterizes the degree of } \\
\text { resource endowment of an economic } \\
\text { entity at the end point of time in } \\
\text { comparison with the predicted } \\
\text { requirements of the external } \\
\text { environment. It can characterize } \\
\text { whether it was possible to increase the } \\
\text { potential of an economic entity to } \\
\text { achieve the predicted requirements of } \\
\text { the external environment. Indirectly } \\
\text { characterizes the performance of an } \\
\text { economic entity }\end{array}$ \\
\hline $\mathrm{PV}_{\mathrm{f}} / \mathrm{PV}_{0}$ & $\begin{array}{l}\text { The rate of change in the } \\
\text { potential of an economic entity during } \\
\text { the adaptation actions }\end{array}$ & $\begin{array}{l}\text { Characterizes the ability of an } \\
\text { economic entity to increase its potential } \\
\text { or resource capacity }\end{array}$ \\
\hline $\mathrm{AV}_{0} / \mathrm{PV}_{\mathrm{f}}$ & $\begin{array}{l}\text { Resultativeness of an } \\
\text { economic entity at the initial moment } \\
\text { of time, taking into account the final } \\
\text { potential opportunities }\end{array}$ & $\begin{array}{l}\text { The degree of achievement of } \\
\text { the final potentially possible results of } \\
\text { the activity of an economic entity at the } \\
\text { beginning of adaptation actions. } \\
\text { Indirectly characterizes the ability to } \\
\text { predict the potential of an economic } \\
\text { entity or its resource capacity }\end{array}$ \\
\hline$P V_{f} / D V_{f}$ & $\begin{array}{l}\text { Resource capacity of an } \\
\text { economic entity at the time of } \\
\text { changing the influence of an external } \\
\text { factor }\end{array}$ & $\begin{array}{l}\text { Characterizes the actual } \\
\text { potential for achieving the requirements } \\
\text { of the external environment }\end{array}$ \\
\hline$A V_{\mathrm{f}} / \mathrm{DV}_{0}$ & $\begin{array}{l}\text { Resultativeness of an } \\
\text { economic entity in relation to the } \\
\text { initial requirements of the external } \\
\text { environment }\end{array}$ & $\begin{array}{l}\text { The degree to which the } \\
\text { actual final results of activities } \\
\text { correspond to the predicted } \\
\text { requirements of the external } \\
\text { environment. Ability to achieve goals }\end{array}$ \\
\hline $\mathrm{AV}_{\mathrm{f}} / \mathrm{PV}_{0}$ & $\begin{array}{l}\text { Resultativeness of an } \\
\text { economic entity with the initial } \\
\text { potential capabilities of an economic } \\
\text { entity }\end{array}$ & $\begin{array}{l}\text { Characterizes the degree of } \\
\text { implementation of the planned task (the } \\
\text { initial potential of an economic entity) }\end{array}$ \\
\hline $\mathrm{AV}_{\mathrm{f}} / \mathrm{AV}_{0}$ & $\begin{array}{l}\text { The rate of change in the } \\
\text { performance of an economic entity }\end{array}$ & $\begin{array}{l}\text { Characterizes the degree of } \\
\text { change in the actual performance of an } \\
\text { economic entity as a result of adaptation } \\
\text { actions }\end{array}$ \\
\hline
\end{tabular}




\begin{tabular}{|c|l|l|l|}
\hline $\mathrm{AV}_{\mathrm{f}} / \mathrm{DV}_{\mathrm{f}}$ & $\begin{array}{l}\text { Compliance with the } \\
\text { external environment at the time of } \\
\text { changing the influence of the } \\
\text { environmental factor }\end{array}$ & $\begin{array}{l}\text { The actual degree of } \\
\text { compliance of the performance of an } \\
\text { economic entity with the requirements } \\
\text { of the external environment }\end{array}$ \\
\hline $\mathrm{AV}_{\mathrm{f}} / \mathrm{PV}_{\mathrm{f}}$ & $\begin{array}{l}\text { Resultativeness of an } \\
\text { economic entity at the time of } \\
\text { changing the influence of an } \\
\text { environmental factor }\end{array}$ & $\begin{array}{l}\text { Resultativeness of an } \\
\text { economic entity at the time of changing } \\
\text { the influence of an environmental } \\
\text { factor. Characterizes the degree of } \\
\text { realization of the potential of an } \\
\text { economic entity }\end{array}$ \\
\hline
\end{tabular}

After analyzing Table 3, it can be concluded that all considered absolute and relative differences between the results of the activity of an economic entity, which change over time under the influence of adaptation actions, can be grouped as follows:

- indicators characterizing the ability to predict during adaptation;

- indicators characterizing resource capacity during adaptation;

- indicators characterizing the performing activity of an economic entity (the ability to perform planned tasks);

- indicators characterizing the success of the implementation of adaptation actions.

The expressions presented in Table 4 comprehensively characterize the components that can affect the resultativeness of adaptation of an economic entity, specifically: the ability to predict, resource capacity, resultativeness of an economic entity, the ability to implement adaptation actions. But it is worth noting that the adaptive capabilities of an economic entity can be represented as the resultativeness of performing activity and the resultativeness of resource provision.

Table 4: Components of adaptation resultativeness and a list of expressions describing them

\begin{tabular}{|c|c|c|}
\hline $\begin{array}{l}\text { Components of adaptation } \\
\text { resultativeness }\end{array}$ & $\begin{array}{l}\text { List of expressions } \\
\text { (absolute } \\
\text { differences) }\end{array}$ & $\begin{array}{l}\text { List of expressions } \\
\text { (relative } \\
\text { differences) }\end{array}$ \\
\hline Forecasting resultativeness & $\mathrm{DV}_{\mathrm{f}-}-\mathrm{DV}_{0} ; \quad \mathrm{PV}_{\mathrm{f}^{-}}$ & 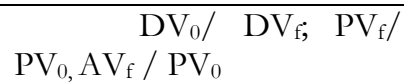 \\
\hline sultativeness & $\begin{array}{l}\mathrm{DV}_{0^{-}} \quad \mathrm{PV}_{0} ; \mathrm{DV}_{0^{-}} \\
\mathrm{PV}_{\mathrm{f}} ; \mathrm{DV}_{\mathrm{f}^{-}} \mathrm{PV}_{0} ; \mathrm{PV}_{\mathrm{f}}-\mathrm{PV}_{0} ; \\
\mathrm{DV}_{\mathrm{f}^{-}} \mathrm{PV}_{\mathrm{f}} ;\end{array}$ & $\begin{array}{l}\mathrm{PV}_{0} / \\
\mathrm{PV}_{0} / \mathrm{DV}_{\mathrm{f}} ; \mathrm{PV}_{\mathrm{f}} / \mathrm{DV}_{0} ; \mathrm{PV}_{\mathrm{f}} / \\
\mathrm{PV}_{0} ; \mathrm{PV}_{\mathrm{f}} / \mathrm{DV}_{\mathrm{f}} ;\end{array}$ \\
\hline $\begin{array}{l}\text { Resultativeness of performing } \\
\text { activities }\end{array}$ & $\begin{array}{l}\quad \mathrm{PV}_{0-}-\mathrm{AV}_{0} ; \quad \mathrm{PV}_{0^{-}} ; \\
\mathrm{AV}_{\mathrm{f}} ; \mathrm{PV}_{\mathrm{f}}-\mathrm{AV}_{0} ; \mathrm{AV}_{\mathrm{f}}-\mathrm{AV}_{0} ; \\
\mathrm{PV}_{0^{-}} \mathrm{AV}_{\mathrm{f}} ;\end{array}$ & $\begin{array}{l}\quad \mathrm{AV}_{0} / \mathrm{PV} ; \mathrm{AV}_{0} / \\
\mathrm{PV}_{\mathrm{f}} ; \mathrm{AV}_{\mathrm{f}} / \mathrm{PV}_{0} ; \mathrm{AV}_{\mathrm{f}} / \mathrm{AV}_{0} ; \\
\mathrm{AV}_{\mathrm{f}} / \mathrm{PV}_{\mathrm{f}}\end{array}$ \\
\hline Adaptive capabilities & $\begin{array}{r}\mathrm{DV}_{0^{-}} \mathrm{AV}_{0} ; \mathrm{DV}_{0^{-}} \\
\mathrm{AV}_{\mathrm{f}} ; \mathrm{DV}_{\mathrm{f}^{-}} \mathrm{AV}_{0} ; \mathrm{DV}_{\mathrm{f}^{-}} \mathrm{AV}_{\mathrm{f}}\end{array}$ & 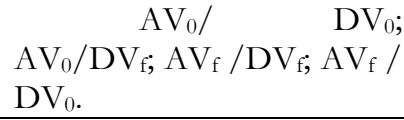 \\
\hline
\end{tabular}

In further calculations that make up the resultativeness of adaptation, we propose to take relative expressions, because they are more objective, and the values at the end of the study period, because we evaluate the already obtained results of adaptation and its resultativeness. In this case, table 4 will take the form of table 5 . 
Table 5: Components of adaptation resultativeness

\begin{tabular}{|l|c|}
\hline Components of adaptation resultativeness & Calculation \\
\hline Forecasting resultativeness & $\mathrm{AV}_{\mathrm{f}} / \mathrm{PV}_{0}$ \\
\hline Resource resultativeness & $\mathrm{PV}_{\mathrm{f}} / \mathrm{DV}_{\mathrm{f}}$ \\
\hline Resultativeness of performing activities & $\mathrm{AV}_{\mathrm{f}} / \mathrm{PV}_{\mathrm{f}}$ \\
\hline
\end{tabular}

\section{Results and Discussion}

If we consider the study of A.I. Oleksyuk, who studies the resultativeness of economic processes at different levels of socio-economic systems, then he proposed a ternary information-centered model for assessing the resultativeness of economic processes. It is based on the following logical elements: result, time, information and resources (Oleksyuk, 2008). As we can see, the conclusions drawn by the authors are similar to those of O. I. Oleksyuk. So, we can draw parallels: resultativeness of the activity - the resultativeness of the performing actions; information - forecasting resultativeness; resources - resultativeness of resource provision.

Consequently, it can be argued that resultativeness is a function of 3 variables: forecasting resultativeness $(\mathrm{FE})$, resource provision resultativeness (RE), performance resultativeness (PE), and values of performance indicators of an economic entity at the beginning of the study period $\left(\mathrm{AV}_{0}, \mathrm{PV}_{0}, \mathrm{DV}_{0}\right)$. This can be expressed using formula (3):

$$
\mathrm{R}=\mathrm{f}\left(\mathrm{AV}_{0}, \mathrm{PV}_{0}, \mathrm{DV}_{0}, \mathrm{FE}, \mathrm{RE}, \mathrm{PE}\right)
$$

In such a case, a definition of the resultativeness of adaptation can be provided.

The resultativeness of adaptation describes the measure of change in the inconsistency of the state of an economic entity with the external environment using a relative indicator, has a complex nature (as a characteristic, it describes the ability of an economic entity to adapt over time, how a property determines the ability of an economic entity to adapt at a particular point in time) and depends on the resultativeness of forecasting, performing activities and resource provision of the activity of an economic entity during adaptation actions.

Note that the planned result of adaptation, i.e. a minimum of inconsistency between economic entities and the external environment, which gives $100 \%$ resultativeness of adaptation, can be achieved under the following conditions:

$$
R \rightarrow \max \text { at }\left\{\begin{array}{l}
F E \rightarrow \max \\
R E \rightarrow \max \\
P E \rightarrow \max
\end{array}\right.
$$

Note that all three groups of indicators are controllable parameters that have an impact on the resultativeness of adaptation. It makes sense to conduct a study to determine the dependence of resultativeness on these groups of parameters. This is also due to the fact that funds are needed to improve certain indicators, and usually 
they are not enough to improve all three groups of indicators. An economic entity faces a choice: given the actual state of the economic entity's activities and a likely change in the influence of the external environmental factor, what to spend the available funds on in order to obtain the highest adaptation resultativeness possible for this economic entity, or how to optimize the costs of adaptation with a satisfactory adaptation resultativeness?

In order to comprehensively characterize the resultativeness of adaptation of an economic entity to changes in the external environment, including digitalization, and to provide the leadership of an economic entity with an information base for making managerial decisions on adaptation, we propose to approach the determination of the adaptation resultativeness from two sides. In previous studies, we found that the adaptation resultativeness, according to the definition, "resultativeness" and "the result of adaptation", can be found by formula (2).

At the same time, as it was determined, the value of adaptation results and, accordingly, resultativeness is a function of three variables - formula (3). That is, we came to the definition of the resultativeness of adaptation using two research methods: deductive (from the general definition of resultativeness to the resultativeness of adaptation) and inductive (we considered the relationship between the results of the activity of an economic entity, which were formed under the influence of the adaptation process, between the options of inconsistency with the external environment, and the conclusion regarding the variables on which the adaptation resultativeness depends) (Fig. 2) (Gonshakov, 2011).

\begin{tabular}{|ll|}
\hline \multicolumn{2}{|c|}{ Deductive research method } \\
\hline \multicolumn{2}{|c|}{ Adaptation efficiency } \\
$\boldsymbol{\downarrow}_{\text {Actual }}$ & \multicolumn{1}{|c|}{ Planned } \\
adaptation & adaptation \\
result & result \\
& \\
\hline
\end{tabular}

\begin{tabular}{|c|c|c|}
\hline \multicolumn{3}{|c|}{ Inductive research method } \\
\hline & daptation & iency \\
\hline $\begin{array}{l}\text { Fore- } \\
\text { casting } \\
\text { efficiency }\end{array}$ & $\begin{array}{l}\text { Resoürce } \\
\text { efficiency }\end{array}$ & $\begin{array}{l}\quad \downarrow \\
\text { Efficiency } \\
\text { of perfor- } \\
\text { ming } \\
\text { activities }\end{array}$ \\
\hline
\end{tabular}

Figure 2. Results of the deductive and inductive methods of studying the adaptation resultativeness

But these two expressions characterize the same value - the resultativeness of adaptation of an economic entity to changes in the external environment. In this case, expression (5) will be valid:

$$
\mathrm{R}_{\mathrm{d}}=\mathrm{R}_{\mathrm{i}}
$$

$$
\frac{\left|\mathrm{DV}_{\mathrm{f}}-\mathrm{AV}_{\mathrm{f}}\right|-\left|\mathrm{DV}_{0}-\mathrm{AV}_{0}\right|}{\left|\mathrm{DV}_{\mathrm{f}}-\mathrm{PV}_{\mathrm{f}}\right|-\left|\mathrm{DV} V_{0}-\mathrm{AV}_{0}\right|}=\frac{|1-\mathrm{PE} \cdot \mathrm{RE}| \cdot \mathrm{FE} \cdot \mathrm{PV}_{0}-\left|\mathrm{DV}_{0}-\mathrm{AV}_{0}\right| \cdot \mathrm{PE} \cdot \mathrm{RE}}{|1-\mathrm{RE}| \cdot \mathrm{FE} \cdot \mathrm{PV} V_{0}-\left|\mathrm{DV}_{0}-\mathrm{AV}_{0}\right| \cdot \mathrm{PE} \cdot \mathrm{RE}}
$$

where $R_{d}$ - formula for the resultativeness of adaptation, determined by a deductive research method; 
$\mathrm{R}_{\text {и }}$ - formula for the resultativeness of adaptation, determined by an inductive research method.

When considering expression (5), one can notice that the left half of the expression can be accurately calculated, and to calculate the right half, it is necessary to know exactly how the resultativeness of adaptation depends on the presented three variables. To do this, we carry out an algebraic transformation of Formula (3), taking into account the data in Table 5, i.e. we will express the parameters of formula (3) through the forecasting resultativeness, the resource provision resultativeness and the resultativeness of performing activity. The end result of this transformation can be represented as:

$$
R=\frac{|1-\mathrm{PE} \cdot \mathrm{RE}| \cdot \mathrm{FE} \cdot \mathrm{PV}_{0}-\left|\mathrm{DV}_{0}-\mathrm{AV}_{0}\right| \cdot \mathrm{PE} \cdot \mathrm{RE}}{|1-\mathrm{RE}| \cdot \mathrm{FE} \cdot \mathrm{PV}_{0}-\left|\mathrm{DV}_{0}-\mathrm{AV}_{0}\right| \cdot \mathrm{PE} \cdot \mathrm{RE}}
$$

As we see from formula (6), the resultativeness of adaptation can be represented as a function of the components of the adaptation resultativeness (RE, FE, PE) and parameters characterizing the initial state of an economic entity $\left(\mathrm{DV}_{0}, \mathrm{PV}_{0}, \mathrm{AV}_{0}\right)$.

Let's define the following features:

- in order to achieve full compliance with the requirements of the external environment, the variables on which the resultativeness depends should strive to the maximum;

- the same value of the resultativeness of adaptation of an economic entity to changes in the external environment can be obtained with different combinations of variables.

The last feature gives the enterprise the opportunity to choose: it is necessary to spend money on improving which variables in order to obtain a specific value of the resultativeness of adaptation.

Provided that the adaptation process is carried out constantly, each economic entity is able to form an information base of cases of adaptation and, according to formula (1), calculate the resulting resultativeness of adaptation to changes in the external environment. It is also possible to determine the forecasting resultativeness, the resource provision resultativeness and the resultativeness of performing activities for each of the cases. That is, we can get the following array of information (7):

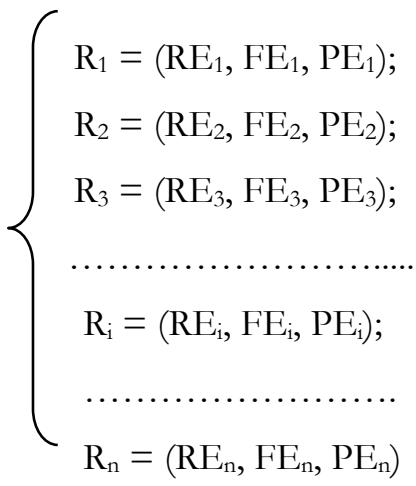


With the help of the given array of information and using optimization methods for the function of several variables, it becomes possible to manage the resultativeness of adaptation based on the optimization of the indicator of the adaptation resultativeness and its costs (Fig. 3).

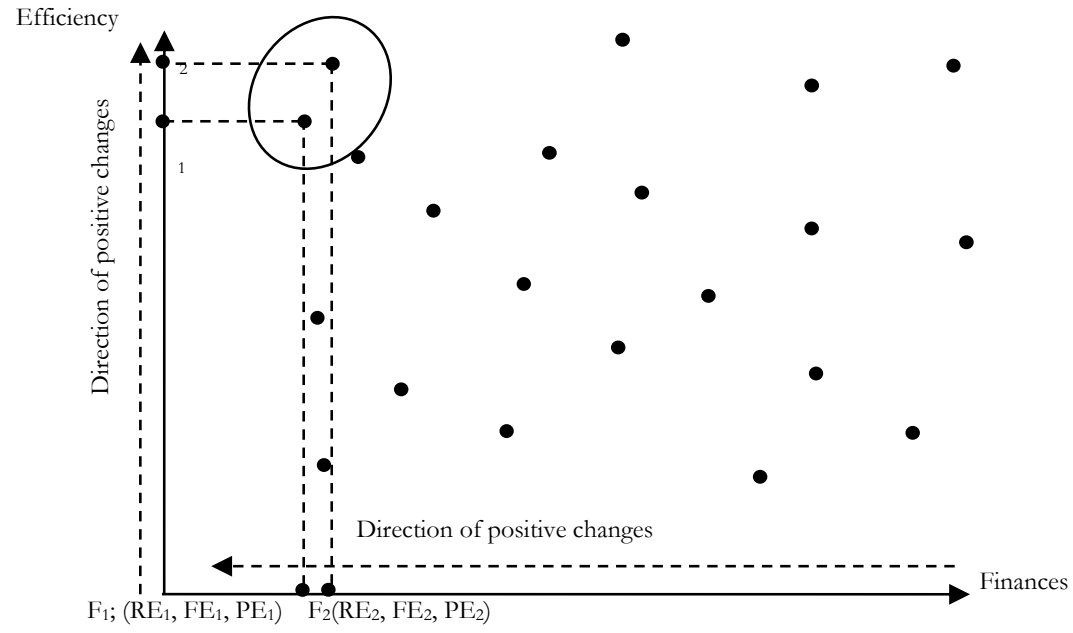

Figure 3. Selection of the highest possible resultativeness of adaptation at the lowest possible cost of financial resources As one can see from Figure 3, it is beneficial for an economic entity to choose options with an resultativeness value of $\mathrm{R}_{1}$, to which corresponds a combination of options for variables $\left(\mathrm{RE}_{1}, \mathrm{FE}_{1}, \mathrm{PE}_{1}\right)$ with the lowest financial costs $\mathrm{F}_{1}$, and $\mathrm{R}_{2}$, to which corresponds a combination of options for variables $\left(\mathrm{RE}_{2}, \mathrm{FE}_{2}, \mathrm{PE}_{2}\right)$ with financial costs $\mathrm{F}_{2}$. In the first case, we will get the lowest financial costs, but not the highest resultativeness. In the second case, we will get the highest possible value for the resultativeness, but the financial costs will be higher than in the first option. In this case, the management of the economic entity must decide which option is more suitable for them. The following factors will be decisive:

the availability of funds that can be spent on improving the resultativeness of adaptation;

the importance of high adaptation resultativeness for an economic entity in each individual case.

It is also needed to be remember about the law of marginal utility, which can be applied to the expenditure of financial resources to improve the resultativeness of adaptation (Fig. 4). 


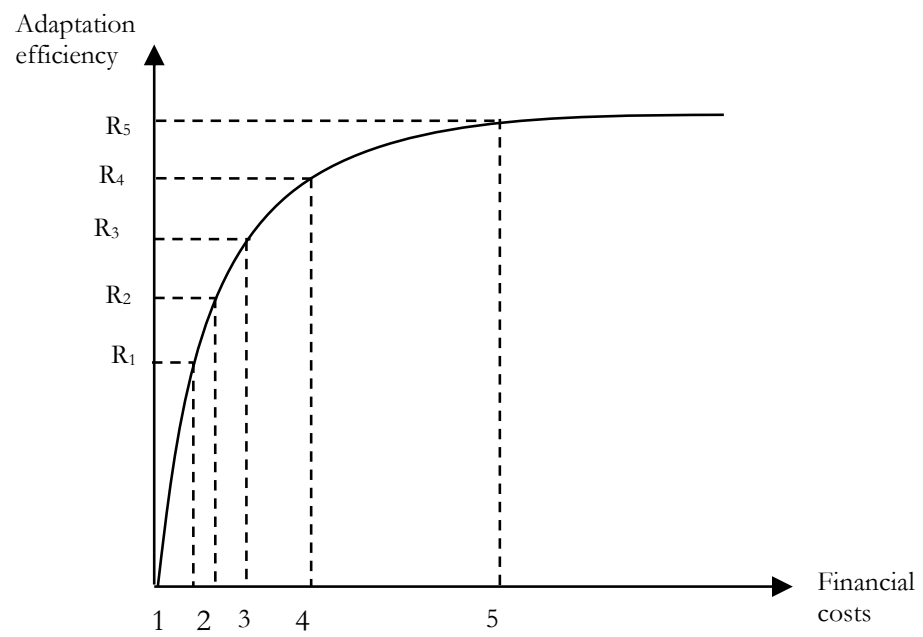

Figure 4. The marginal utility of spending financial resources to improve the resultativeness of adaptation

As you can see from Figure 4, the higher the adaptation resultativeness we want to achieve, the more financial resources need to be invested to increase the adaptation resultativeness by one conventional unit.

But there may be cases when the same value of resultativeness can be obtained with different variants of combinations of variables, which means that it is possible to track such cases and offer recommendations regarding the appropriateness of each of the variants of combinations of variables, taking into account the finances that were spent on the adaptation. This information will be necessary in the future to obtain the maximum possible resultativeness of adaptation with minimal financial costs, which is illustrated in Figure 5.

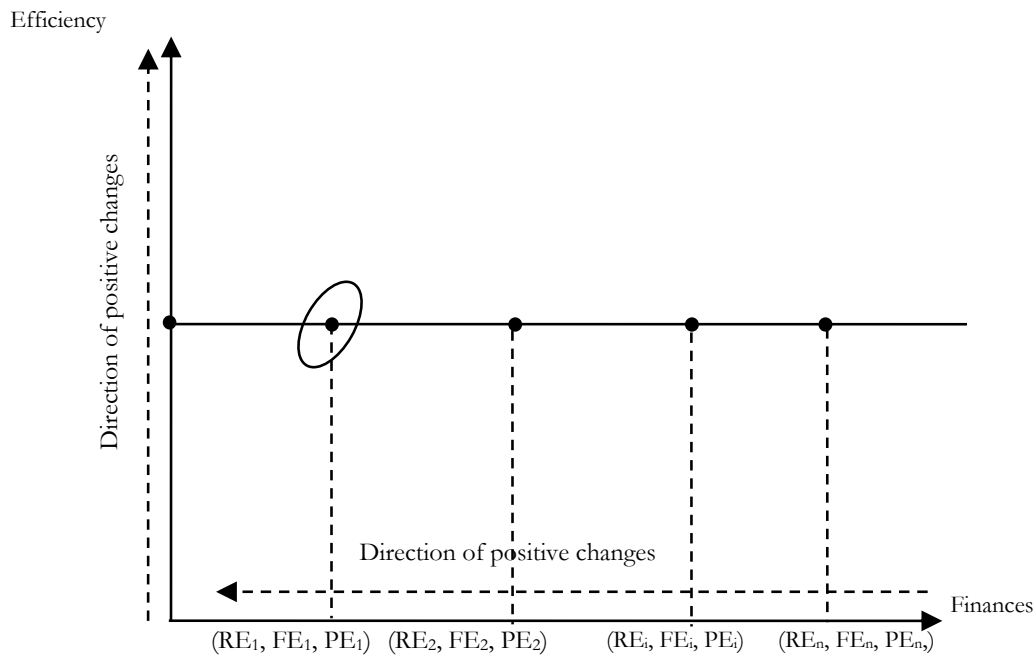

Figure 5. The value of the resultativeness of adaptation for various combinations of variables that affect it 
As we can see from Figure 5, the same value of the resultativeness can be obtained by investing different amounts of financial resources, which will correspond to different sets of combinations of variables that affect the resultativeness of adaptation. It is clear that with an equal value of the resultativeness, the option with minimal financial costs is more profitable for an economic entity. In Figure 5, this is the option with the value of the variables $\left(\mathrm{RE}_{1}, \mathrm{FE}_{1}, \mathrm{PE}_{1}\right)$. The question is how to find the best option, because the use of data in the form of an array prevents the use of optimization methods. For many of them, it is necessary to use data in the form of analytical dependencies. For this, we will develop an algorithm for approximating the reduced data to analytical dependences. It is very important that the funds are used not to ensure a specific value of the resultativeness component, but to change its value relative to the previous period. Therefore, it is recommended to find the dependence of the change in the adaptation resultativeness components $\left(\Delta \mathrm{R}_{\mathrm{res}}, \Delta \mathrm{R}_{\mathrm{f}}, \Delta \mathrm{R}_{\mathrm{per}}\right)$ on their costs, since funds are spent exactly to change the value of the activity indicator from the initial to the actual one at the end of the study period. To analyze stochastic dependences, we use the mathematical apparatus of correlation and regression analysis (Ramazanov, 2016). The proposed algorithm is shown in Figure 6.

After obtaining information on the dependencies that make up the resultativeness of adaptation on the costs of adaptation in the context of digitalization, it becomes expedient to find the maximum possible value of resultativeness, provided that the budget for adaptation or the minimum budget remains unchanged, which will ensure the maximum resultativeness of adaptation in the context of digitalization. With the help of the Nelder-Mead simplex method, it is possible to find the maximum possible value of the resultativeness, provided that the budget for adaptation or the minimum budget remains unchanged, which will ensure the maximum resultativeness of adaptation in the context of digitalization.

The algorithm for finding the optimal value of the resultativeness of adaptation in the context of digitalization and its costs is shown in Figure 7. 


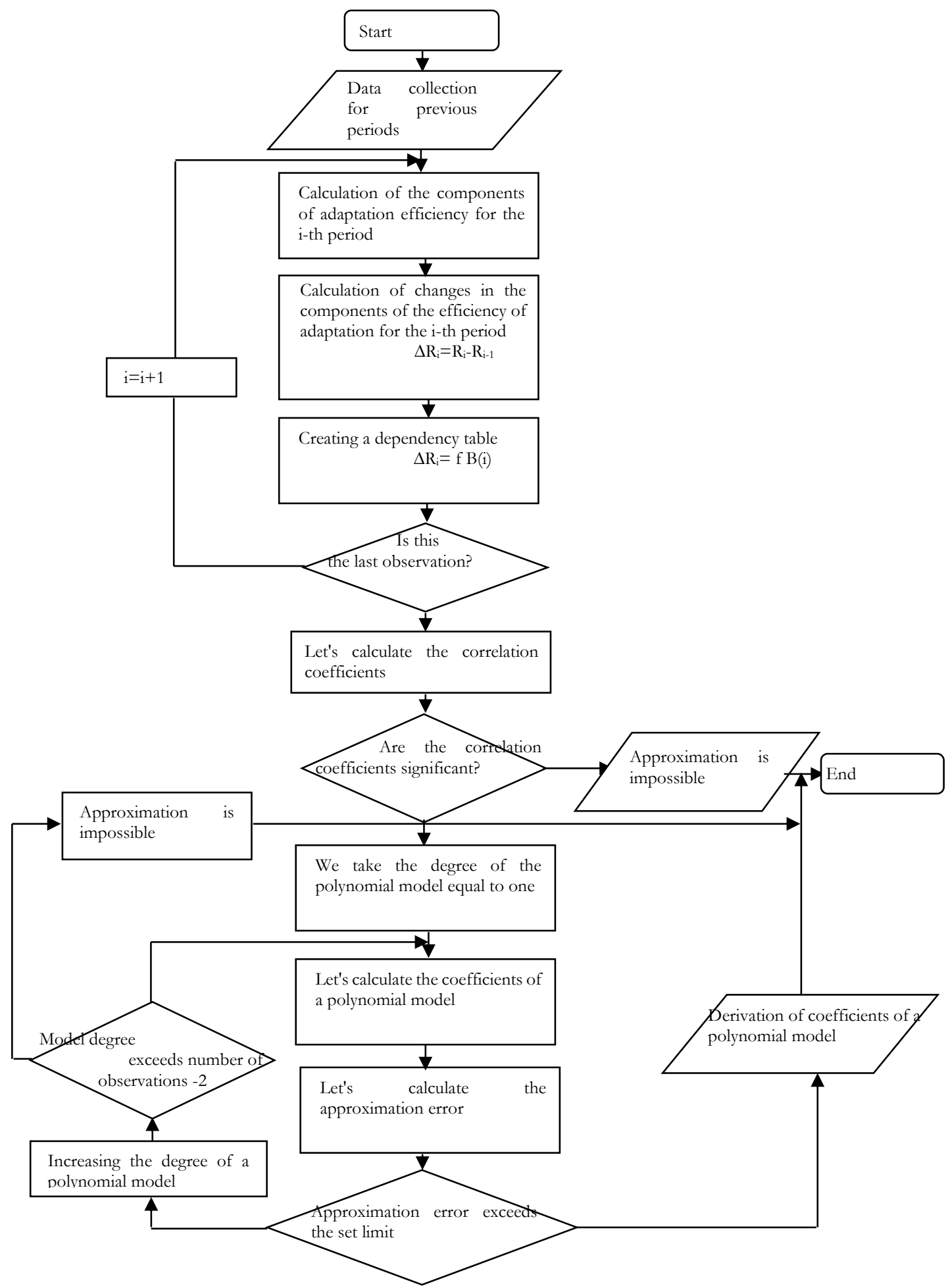

Figure 6. Algorithm for analyzing the dependence of the components of adaptation resultativeness on costs Published by ECSDEV, Via dei Fiori, 34, 00172, Rome, Italy 


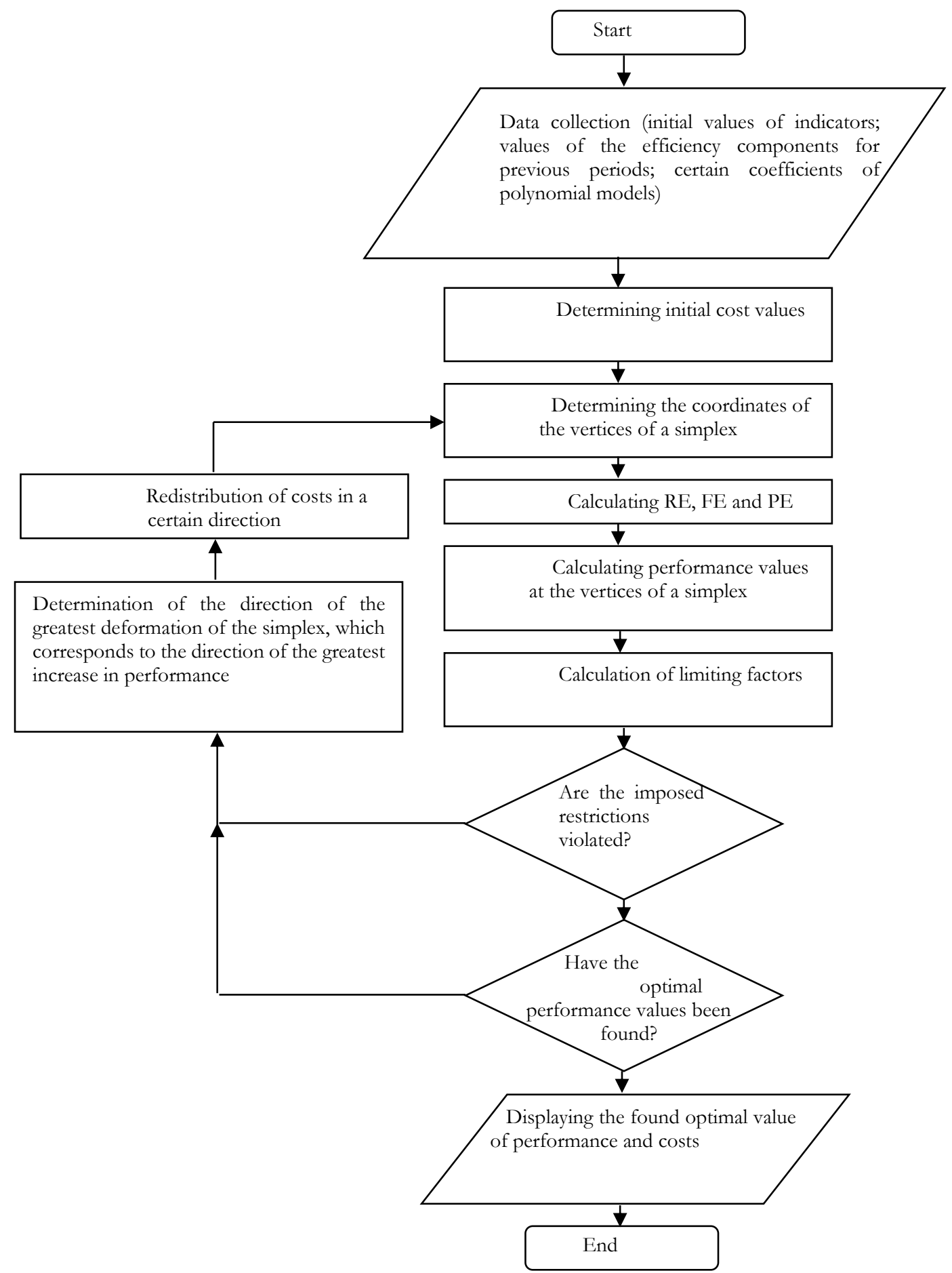

Figure 7. Algorithm for finding the optimal value of the adaptation resultativeness in the context of digitalization and its cost 
The algorithm proposed in Figure 7 will allow, based on the calculation of the quantitative value of the resultativeness of adaptation of an enterprise and a retrospective analysis of the components of the resultativeness and costs of adaptation using the NelderMead simplex method, determining the optimal value of the resultativeness of adaptation in the context of digitalization and its costs (Bundy, 1988).

\section{Conclusion}

Thus, it is possible to optimize the resultativeness of adaptation of an economic entity to the conditions of digitalization by performing the following steps:

1) calculating the values of the resultativeness of adaptation and its components: forecasting resultativeness, resource provision resultativeness and resultativeness of performing activities;

2) using the algorithm for analyzing the dependence of the components of the resultativeness of adaptation on the costs of adaptation, determine and analyze these dependencies in the context of digitalization;

3) calculate the maximum possible value of the resultativeness under the condition of a constant budget for adaptation or the minimum budget, which will ensure the maximum resultativeness of adaptation using the algorithm for finding the optimal value of the resultativeness of adaptation to the conditions of digitalization and its costs. Achieving the optimal value of the resultativeness of adaptation to digitalization conditions will increase economic security by optimizing the costs of adaptation, which will increase the competitiveness of an economic entity in a digitalization environment, ensure the functioning of an economic entity and its further development with the successful use of modern information and communication technologies in its activities.

\section{References}

Afanasyev, M.A., Staroverova, O.V., \& Urintsov, A. (2016). Adaptation as a process of managing a business entity. Vestnik of the Moscow University of the Ministry of Internal Affairs of Russia, (2).

Bundy, B. (1988). Optimization methods: Introductory course: Transl. from English Radio and communication.

Cokins, G. (2015). Resultativeness management: How to bridge the gap between the announced strategy and the real processes. Alpina Publisher.

Darmits, R. Z., \& Vatsik, N. O. (2010). Relationship between resultativeness and economic resultativeness in the enterprise management system. Scientific Bulletin of NLTU of Ukraine, 20(12).

Drucker, P. F. (2007). Management challenges for the 21st century. Routledge.

Gonshakov, A. G. (2011). Methods of forming indicators for evaluating the effectiveness of innovation and investment projects (Doctoral dissertation, Vladimir State University).

Kachalov, V. A. (2007). What is a "continuous improvement in the resultativeness of the QMS"? Quality management methods, (1), 28-32.

Khalin, V. G., \& Chernova, G. V. (2018). Digitalization and its impact on the Russian economy and society: advantages, challenges, threats and risks. Management consulting, (10 (118))

Kuntzman, A. A. (2017). The specifics of the adaptation of modern companies to the conditions of the digital economy. Innovation, (9 (227)).

Kuntzman, A. A. (2016). Transformation of the internal and external business environment in the digital economy. Management of economic systems: an electronic scientific journal, (11 (93)).

Oleksyuk, O. I. (2008). Economics of enterprise resultativeness: a monograph. K.: KNEU, 362(6).

Ramazanov, S. K. (2016). Environmental and economic enterprise management tools. 
Robbins, Stephen P, Coulter, Mary. Management, 8 edition: in Russian translation - İ: the Publishing house «Williams», 2007. - $1056 \mathrm{p}$

Valenduk, G., \& Vendramin, P. (2016). Working in the digital economy: sorting old from new (Volume 3). Brussels: European Trade Union Institute.

Wetherbe, J. C., McLean, E. R., Leidner, D. E., \& Turban, E. (2006). Information technology for management: Transforming organizations in the digital economy. J. Wiley. 